\title{
The Investigation of "MissFit" as Android - Based Daily and Healthy Drink Application
}

\author{
Dwi Cahyo Kartiko ${ }^{1, *}$ Setya Chendra Wibawa ${ }^{2,}$ Aisyah Fitri Azzahrah ${ }^{3}$
}

\author{
${ }^{1}$ Physical Education, Health and Recreation Study Program, Universitas Negeri Surabaya \\ ${ }^{2}$ Information Technology Education Study Program, Universitas Negeri Surabaya \\ ${ }^{3}$ Nutrition Study Program, Universitas Negeri Surabaya \\ *Corresponding author. Email: dwicahyo@unesa.ac.id
}

\begin{abstract}
The imbalance of caloric intake that enters the body will lead to diseases and health problems that hinder human productivity. One of the efforts taken to balance the intake of calorie consumption is to have related information. Along with the times and technology that can be grasped by almost everyone in Indonesia, various information can be easily obtained. The purpose of this study was to develop and determine the feasibility of a daily healthy drink menu application by providing calorie information and the dose of drinks that can be consumed based on the android " MissFit. " The development of the MissFit application uses the ADDIE method whose stages include 1) Analysis, 2) Design, 3) Development, 4) Implementation, 5) Evaluation. The results of this study are based on the pie chart; understandability is stated to be $75 \%$ good and $20 \%$ perfect, while Learnability states $50 \%$ is good, and $50 \%$ is perfect. On the pie chart, the operability of $50 \%$ is good, and $40 \%$ is perfect, while the Functionality is $60 \%$ good and $40 \%$ perfect. The application's content is stated to be $60 \%$ good and $40 \%$ perfect, and $50 \%$ of the respondents are from the State University of Surabaya, and $50 \%$ are outside the State University of Surabaya. So it can be concluded that the investigation of applications that provide calorie information, as well as the dose of healthy drinks that can be consumed daily based on Android, it is necessary to design an application that is made more attractive and easy to understand so that users feel interested and use it effectively easy. The "MissFit" application was feasible with excellent and perfect criteria of $96 \%$.
\end{abstract}

Keywords: Health apps, Calorie information, Android

\section{INTRODUCTION}

Eating and drinking are an absolute necessity carried out daily to fulfill the body's needs to carry out activities[1]. The body needs body fuel for various activities. The action in question is our working capacity every second[2]. The power required for energy fulfillment in daily activities is calories. A calorie is a general term for the unit of energy in the metric system. Our bodies need calories from the food we eat as a source of energy to carry out daily activities. Without enough calories, we will feel weak like a car without gasoline[3]. Calories can also be interpreted as a unit used to measure the value of energy or energy, the calorie content in a food depends on the content of carbohydrates[4], protein. Sources of calories can come from food and drinks[5] that we consume with different nutritional content such as fat, carbohydrates, protein[4], etc. Each person's calorie needs vary, depending on age, height, weight, and activities carried out every day. The balance of calories[6] in the body is essential to affect a person's health. Lack of calories can cause malnutrition, while excess nutrition can cause obesity. Obesity is an imbalance between calorie consumption and energy needs, where consumption is too much compared to consumption[7]. Body weight[8] is a significant public health problem associated with several chronic conditions, including heart disease, hypertension, hyperlipidemia, diabetes, hyperinsulinemia, and cancer. Meanwhile, if the body lacks calories, it will also cause the body to become weak and underweight[9].

One of the efforts to balance the number of calories consumed by the body is to consider calorie intake. Taking into account the daily calorie needs of the body is very important. Usually, people will go on a $\operatorname{diet}[10]$ or adjust their diet to regulate the number of calories in the body. There are many kinds of diet methods used by humans, and one of them is through a technology-based approach[11][12][13][14][15]. One of the ways to calculate the amount of calorie intake that will be consumed is by using an application specifically 
designed to fulfill information related to the calories of food and beverages consumed daily. The MISFIT app is one of those apps designed to take into account the calorie intake in drinks.

MISFIT is a daily healthy drink menu application that provides calorie information and the number of drinks that can be consumed. This application is based on Android. The name MissFit comes from the acronym for Daily and Healthy Drinks (FIT). MissFit means "not right" because this application is inspired by the dose of drinks that do not match your needs. Based on the above explanation, research was carried out to develop applications that provide information related to calories in healthy drinks consumed daily and the dose of drinks that can be taken into consideration for consumption.

\section{METHODS}

The method used in assessing the MissFit application is ADDIE (Analysis, Design, Develop, Implement, and Evaluate). ADDIE is a concept in product development, a series of stages that have their respective goals, which will be explained in detail as follows[16]:

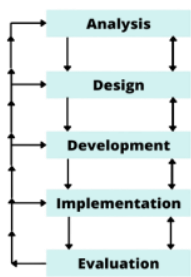

Figure 1. ADDIE Model stages[17]

The ADDIE (Analysis, Design, Develop, Implement, and Evaluate) model has similarities with the Waterfall model in software development related to application development theory. The following are the stages of the ADDIE model, which include Analysis, Design, Develop, Implement, and Evaluate[17]:

\subsection{Analysis}

Improvement to achieve excellent and maximum goals. The system analysis stage is the stage where the description of a complete system in components to identify and evaluate problems in the development of applications that provide information related to the nutritional value of healthy drinks consumed daily, especially information pertaining to the number of calories based on Android, can be carried out. In this analysis stage, a needs analysis process is carried out for the system on the application of information on the number of calories for healthy drinks based on Android.

\subsection{Design}

At this stage, a design will be made on the system's daily healthy drink menu by providing calorie information and the number of drinks consumed. In this design, it is expected that users can quickly and easily access information related to the desired beverage product. Inapp web views daily healthy drink menu by providing calorie information and the number of drinks that can be consumed. There needs to be a design that is made attractively but still easy to use, such as display or specific information such as information on calories and quantities that can be consumed in drinks to feel comfortable and understand when accessing or using them.

\subsection{Develop}

In this stage, a process is carried out to realize the design steps that have been designed into an application. The development stage can also be said to be the coding stage. What is done at the development stage is to analyze the users on the system and what each user does to the system.

\subsection{Implement}

At this stage is the step where testing of the application is carried out daily healthy drink menu by providing calorie information and the number of drinks that can be consumed, which has been made in the development stage. Testing for this application using software standards that have been provided or already exist.

\subsection{Evaluate}

This stage aims to determine the suitability and success of the evaluation of the results of the implementation of the application that has been made. The application that has been made can be said to be successful if it is by the criteria and standards that have been previously set.

\section{RESULTS AND DISCUSSION}

This research produces a product in the form of an application that provides calorie information and the dose of healthy drinks that can be consumed daily, which is named MISFIT. This application is based on Android on a web page and can be accessed via a link or barcode scan. The development of this MISFIT application uses the ADDIE development model, which consists of several stages as follows:

\subsection{Analysis}

(1) the analysis of mobile phone users is increasing every year, (2) analysis of situations or circumstances where there are currently many diseases caused by an imbalance in caloric intake sourced from food and beverages consumed daily, and (3) market analysis of healthy 
beverage products is back in vogue to meet nutritional needs during the pandemic.

\subsection{Design}

(1) designing the concept of an application model of the number of calories and the dose of healthy drinks that will be developed, (2) looking for information about the number of calories and the limit on the number of doses that can be tolerated by the human body from various works of literature, (3) designing the appearance of the application daily healthy drink menu by providing calorie information, as well as the number of drinks that can be consumed which is based on Android with a design that is made as attractive and efficient as possible so that users can use the application comfortably.

\subsection{Develop}

(1) The development and manufacture of the MISFIT application are based on a design that has been designed through glideapps.com in which many templates can be used for free, making it easier to create applications and slightly change the appearance of the template to match the design and concept of the application model. the following display of applications that have been developed:
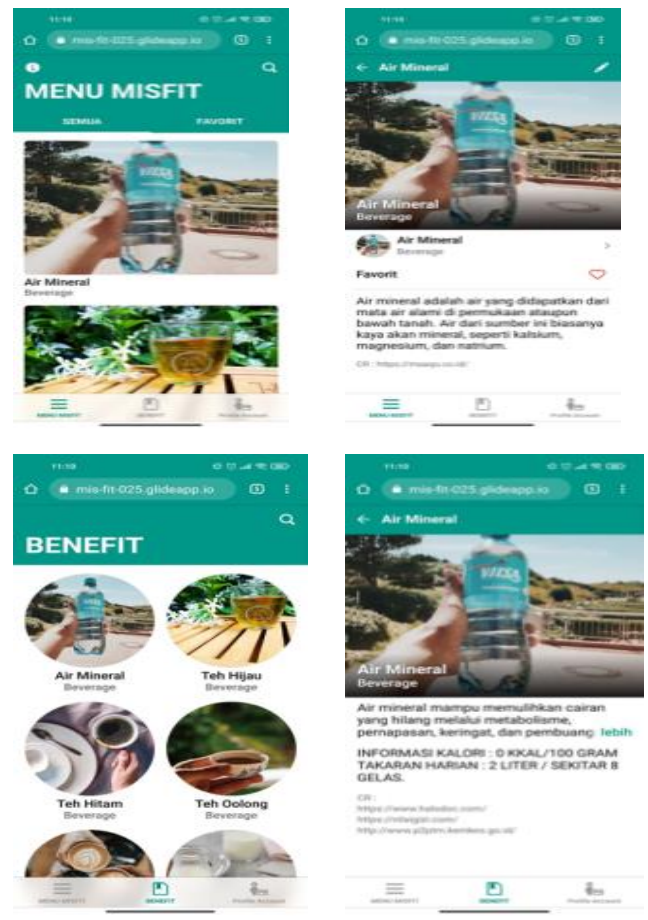

Figure 2. MissFit App

Source: MissFit App (https://mis-fit-025.glideapp.io/)

\subsection{Implement}

(1) Testing the application on the user directly, (2) Carry out the validation process or application feasibility by users and experts.

\subsection{Evaluate}

(1) Create and process a questionnaire about application eligibility, (2) Revise if something doesn't fit

Table 1. Eligibility Criteria[18]

\begin{tabular}{|l|l|}
\hline Information & Answer \\
\hline Very good & $20 \%-50 \%$ \\
\hline Well & $50 \%-75 \%$ \\
\hline Neutral & $5 \%-10 \%$ \\
\hline Not good & $0 \%$ \\
\hline Very Not Good & $0 \%$ \\
\hline
\end{tabular}

Table 1 shows the average scores that fall into the eligibility criteria are in the excellent category outstanding category, with the following averages:

$\bar{X}=\frac{95 \% 100 \% 90 \% 100 \% 95 \%}{5}=96 \%$

\section{QUESTIONNAIRE TESTING}

There are several testing questionnaires[19], such as Nielsen's Attributes of Usability Questionnaire
(NAU)[18]. Still, this questionnaire is not used because ISO 9126-1 is sufficient and similar to NAU to review an application. This test and questionnaire aim to know the quality of the application made whether it has reached feasibility according to the standard to the respondent concerned or not. Respondents involved in this test came from various backgrounds, with the number of respondents as many as 20 
people. Questionnaires and grids conducted from testing in this study were taken based on the ISO 9126-1 standard. There are several characteristics in testing software quality, consisting of the variables Understandability, Learnability, Operability,
Functionality, and Content[20]. The following are the characteristics of ISO 9126-1 in the table, along with the criteria and results. Table 2 shows the indicators of ISO 9126-1 and information on what kind of question each hand.

Table 2. Testing Grid[20]

\begin{tabular}{|c|c|c|}
\hline No & Variable & Information \\
\hline 1 & Understandability (Understood) & Capabilities in software that are easy for us to understand \\
\hline 2 & Learnability (Learned) & Skills in software that are easy for us to learn \\
\hline 3 & Operability (operated) & Capability in software that is easy to operate \\
\hline 4 & Functionality (Function) & $\begin{array}{l}\text { Capabilities in software that provide accurate Functionality, security, } \\
\text { appearance, and data management as they are used }\end{array}$ \\
\hline 5 & Content (content) & $\begin{array}{l}\text { The ability to define the truth, adequacy, suitability of the contents contained } \\
\text { therein. }\end{array}$ \\
\hline
\end{tabular}

The appearance of the "MISFIT" application is attractive so that it is easy for users to understand
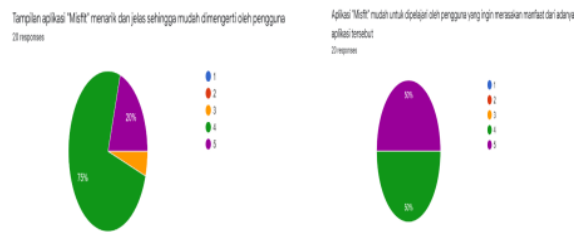

Figure 3. Pie Charts Understandability and Learnability

Based on the pie figure 3 , it can be seen that of the 20 respondents who think Neutrally as much as 5\%, 75\% who think Good and 20\% think Very Good. The "MISFIT" application is easy to learn for users who want to experience the benefits. Based on the pie above, Learnability of the 20 respondents who think Good as much as $50 \%$ and $50 \%$ think Very Good. The ease of the "MISFIT" application to be used/operated by users in daily life.

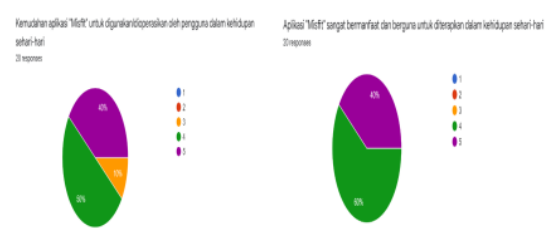

Figure 4. Pie chart Operability and Functionality

Based on the pie figure 4 , it can be seen that of the 20 respondents who think Neutral, as much as 10\%, 50\% who think Good, and $40 \%$ think Very Well. The "MISFIT" application is handy and helpful to be applied in everyday life. Based on the pie above, it can be seen that Functionality of the 20 respondents who think Good as much as $60 \%$ and $40 \%$ think Very Good. The contents of the application "MISFIT: which includes the correctness, suitability, and adequacy of the material contained therein.

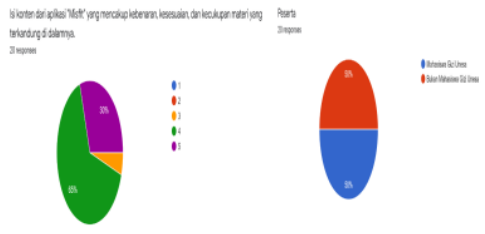

Figure 5. Pie chart Content and Respondent Composition Pie Chart

Based on the pie figure 5, it can be seen that of the 20 respondents who think neutral as much as $5 \%, 60 \%$ feel good, and $40 \%$ think very well. Based on the pie diagram above, it can be seen that the Respondent Composition Pie Chart the background of respondents who are Universitas Negeri Surabaya (Unesa) Nutrition Students is $50 \%$, and respondents who are not Unesa Nutrition Students are $50 \%$. Based on the test results above, it can be concluded that applications that provide calorie information, as well as the dose of healthy drinks that can be consumed daily based on Android, are considered feasible by respondents with an average value of excellent and excellent categories of $96 \%$ according to respondents.

\section{CONCLUSION}

Based on the results of the explanation above, it can be concluded that the investigation of applications that provide calorie information, as well as the dose of healthy drinks that can be consumed daily based on Android, it is necessary to design an application that is made more attractive and easier to understand so that users feel interested and use it effectively easy. As well as the need for the development of the contents of the application such as adding other beverage information that has not been included of the 20 respondents who came from Nutrition Students and not Nutrition Students, they thought that the "MISFIT" application was feasible with 
good and perfect criteria of $96 \%$. Suggestions that can be used as input are developing more attractive designs and adding more beverage information content types.

\section{REFERENCES}

[1] Y. Y. Lam and E. Ravussin, "Analysis of energy metabolism in humans: A review of methodologies," Mol. Metab., vol. 5, no. 11, pp. 1057-1071, 2016, DOI: 10.1016/j.molmet.2016.09.005.

[2] J Galgani and E Ravussin, "Energy metabolism, fuel selection and body weight regulation," Bone, vol. 23, no. 1, pp. 1-7, 2013, DOI: 10.1038/ijo.2008.246.Energy.

[3] L. D. Asih and M. Widyastiti, "Meminimumkan Jumlah Kalori di Dalam Tubuh dengan Memperhitungkan Asupan Makanan dan Aktivitas Menggunakan Linear Progamming," Ekologia, vol. 16, no. 1, pp. 38-44, 2016.

[4] N. Silvis, "Nutritional recommendations for individuals with diabetes mellitus," South African Med. J., vol. 81, no. 3, pp. 162-166, 1992.

[5] M. Nazir, S. Arif, R. S. Khan, W. Nazir, N. Khalid, and S. Maqsood, "Opportunities and challenges for functional and medicinal beverages: Current and future trends," Trends Food Sci. Technol., vol. 88, no. April, pp. 513-526, 2019, DOI: 10.1016/j.tifs.2019.04.011.

[6] J. C. Peters and J. Beck, "Low-Calorie Sweetener (LCS) use and energy balance," Physiol. Behav., vol. 164, pp. 524-528, 2016, DOI: 10.1016/j.physbeh.2016.03.024.

[7] O. asbaghi, S. Kashkooli, R. Choghakhori, A. Hasanvand, and A. Abbasnezhad, "Effect of calcium and vitamin D co-supplementation on lipid profile of overweight/obese subjects: A systematic review and meta-analysis of the randomized clinical trials," Obes. Med., vol. 15, no. July, p. 100124, 2019, DOI: 10.1016/j.obmed.2019.100124.

[8] C. J. Lavie, D. Laddu, R. Arena, F. B. Ortega, M. A. Alpert, and R. F. Kushner, "Healthy Weight and Obesity Prevention: JACC Health Promotion Series," J. Am. Coll. Cardiol., vol. 72, no. 13, pp. 1506-1531, 2018, DOI: $10.1016 /$ j.jacc.2018.08.1037.

[9] D. C. Fonseca et al., "Bodyweight control and energy expenditure," Clin. Nutr. Exp., vol. 20, pp. 55-59, 2018, DOI: 10.1016/j.yclnex.2018.04.001.

[10] Bertha S Burke and Harold C Stuart, "A Method od Diet Analysis,” J. Pediatr., pp. 493-503, 1983.

[11] A. Kristanto, C. Setya, S. Wibawa, and M. T. Pd, "Utilization of Digital Camera Simulation Media."

[12] S. C. Wibawa, I. K. D. Narayana, I. Prismana, D. A. Dermawan, A. Manyu, and A. Frianto, "Designing of Android Based Learning ( Mobile Learning ) for Multidiscipline Students Designing of Android Based Learning ( Mobile Learning ) for Multidiscipline Students," J. Phys. Conf. Ser., vol. 1569, 2020, DOI: 10.1088/1742-6596/1569/2/022015.

[13] Y. S. Rahayu, S. C. Wibawa, Y. Yuliani, E. Ratnasari, and S. Kusumadewi, "The development of BOT API social media Telegram about plant hormones using Black Box Testing," IOP Conf. Ser. Mater. Sci. Eng., vol. 434, no. 1, 2018, doi: 10.1088/1757899X/434/1/012132.

[14] M. S. Sumbawati, R. C. Wibawa, Munoto, and S. C. Wibawa, "Development of Vocational Interactive Multimedia based on Mobile Learning," IOP Conf. Ser. Mater. Sci. Eng., vol. 288, no. 1, 2018, doi: 10.1088/1757-899X/288/1/012101

[15] S. C. Wibawa, I. M. Arsana, Mashudi, M. Sahlan, and F. A. Rachmaningrum, "Development of Vocational Online Examination: A Case Study of Computer Systems," in 1st Vocational Education International Conference (VEIC 2019), 2019, vol. 379, no. Vic, pp. 329-332, DOI: 10.2991/assert.k.191217.053.

[16] R. S. Nadiya and S. Faaizah, "The Development of Online Project-Based Collaborative Learning Using ADDIE Model," Procedia - Soc. Behav. Sci., vol. 195, pp. $\quad 1803-1812, \quad 2015, \quad$ DOI: 10.1016/j.sbspro.2015.06.392.

[17] S. Danks, "The ADDIE Model: Designing, Evaluating Instructional Coach Effectiveness," $A S Q$ Prim. Second. Educ. Br., vol. 4, no. 5, pp. 1-6, 2011.

[18] Khaoula Benmoussa, Majida Laaziri, Samira Khouldji, Mohamed Larbi Kerkeb, and Abir El Yanomami, "Evaluating the Usability of a Moroccan University Research Management Web Platform," Procedia Manuf., vol. 32, pp. 1008-1016, 2019.

[19] M. A. Testa and D. C. Simonson, The Use of Questionnaires and Surveys. Elsevier Inc., 2017.

[20] D. Gade, "The Evaluation of Software Quality," 2013. 